\title{
Design of a Tribo-Simulator for Investigation of the Tribological Behavior of Stainless-Steel Sheets Under Different Contact Conditions
}

\author{
Valmir Dias Luiz, ${ }^{a, b *}$ (1), Paulo César de Matos Rodrigues ${ }^{a}$ \\ ${ }^{a}$ Universidade Federal de Minas Gerais, Programa de Pós-Graduação em Engenharia Mecânica, \\ Av. Antônio Carlos, Pampulha, 31270-901, Belo Horizonte, MG, Brasil. \\ ${ }^{b}$ Centro Federal de Educação Tecnológica de Minas Gerais, Departamento de Metalurgia e Química, \\ R. 19 de Novembro, Centro Norte, 35180-008, Timóteo, MG, Brasil.
}

Received: May 07, 2021; Revised: September 25, 2021; Accepted: October 21, 2021

\begin{abstract}
In sheet metal forming (SMF), deformation is caused by the relative movement between the sheet and tool, which generates friction forces. However, materials behave differently during plastic deformation. In this study, a tribo-simulator was designed to investigate the effect of different contact conditions or formability tests on the tribological behavior of AISI 304 and AISI 430 stainless-steel sheets. The effects of the texture and microstructure of the sheets on the measured coefficients of friction (COFs) and changes that occurred on the tribosurfaces also were investigated. Roughness and microhardness measurements, optical and scanning electron microscopy, and X-ray diffraction were used in the analyses. The tribo-simulator was successfully manufactured, and the repeatability of the measured COFs was satisfactory (standard deviation of $\sim 0.02$ ). A comparative analysis of the formability tests revealed differences in the COFs. In the bending under tension test, the COF for ferritic steel was 33\% higher, while in the strip-tension test, the COF for austenitic steel was $44 \%$ higher. Friction was strongly influenced by the texture and microstructural characteristics of the steel sheets. The samples exhibited galling due to severe adhesive wear.
\end{abstract}

Keywords: Sheet metal forming, AISI 304 and AISI 430 stainless-steel sheets, Tribo-simulator, Formability tests, Coefficients of friction.

\section{Introduction}

In sheet metal forming (SMF) processes, deformation is caused by the relative movement between the sheet and tool, which generates frictional forces. Several authors ${ }^{1-3}$ highlighted that the influence of friction-related aspects has been a primary concern in SMF processes because the frictional forces at the workpiece-tool interface determine the nonuniformity of sheet deformation and surface quality of the final piece. Trzepiecinski ${ }^{2}$ noted that the mechanical properties of the metallic sheet are an important factor, and inadequate consideration of this factor in the design of SMF manufacturing processes causes buckling, excessive thinning, tearing, and wrinkling of the components. However, an extensive amount of research has listed several other factors that affect the final shape of the components, such as the geometry of the tool (e.g., punch-to-die clearance and die and punch radii), technological parameters (e.g., temperature and forming speed), properties of the tool material (e.g., hardness and chemical composition), and friction conditions or contact (e.g., dry or lubricated contact, lubricant type, contact pressure, initial surface topography, and geometry and kinematics of tribocontact) ${ }^{1-9}$.

Because mechanical components are simultaneously subjected to a combination of friction, wear, and corrosion in many applications, Lo et al. ${ }^{10}$ highlighted that stainless steels

*e-mail: valmir@cefetmg.br are commonly used to manufacture parts by SMF owing to their elevated corrosion resistance. The authors noted that there are numerous grades of stainless steel on the market, with each grade offering unique characteristics for use in specific applications, such as in the food, chemical, medical, civil construction, automotive, and home appliance industries. Ferritic stainless steel (FSS) and austenitic stainless steel (ASS) sheets are the most commonly used in this context. Both steel sheets are corrosion resistant; however, different types perform better than the others. According to ISSF ${ }^{11}$, the introduction of nickel in AISI 304 steel makes it substantially more corrosion-resistant than AISI 430 steel; however, it is more expensive. Where cost is a more important factor than life span, AISI 430 steel may be more suitable.

In general, FSS sheets have a higher limiting drawing ratio (LDR) (ratio of the blank diameter/punch diameter) and mean normal anisotropy coefficient $(\bar{R})$ compared to ASS sheets, which indicates greater resistance to deformation in the thickness direction, thus allowing for deeper drawing. However, ASS sheets have a higher limiting dome height $(\mathrm{LDH})$ and lower planar anisotropy coefficient $(\Delta R)$ compared to FSS sheets, which indicates better performance in pure forming by stretching and lower levels of earing, thus producing less waste in the production line $\mathrm{e}^{10-12}$. However, there has not been a comparative study of the tribological 
behavior of these steels under the different contact conditions present in SMF processes.

Evin et al. ${ }^{4,5}$ emphasized that the influence of a single parameter on SMF processes cannot be determined precisely because unique parameters of the material (e.g., texture and microstructure) can influence its tribological behavior from one contact condition to another; therefore, their influence on material formability also varies, making it difficult to obtain exact coefficients of friction (COFs). With the increasing importance of simulation software in pre-production, the need for exact values of input data for numerical simulations has become increasingly important. Therefore, these arguments confirm the need to investigate the tribological behavior of the stainless-steel sheets mentioned above under different contact conditions.

However, according to Trzepiecinski and Lemu ${ }^{9}$, no universal method or tribo-simulator has been developed for determining the COF in SMF processes. This is attributed to the variety of tool geometries in contact with the deformed material, as well as the existence of different stress and strain states in specific areas of the drawn piece. In this context, the authors provided a comprehensive review of developments and trends in friction testing for conventional SMF and incremental sheet forming, such as drawing with tangential compression, bending with tangential compression, the stripdrawing test, the draw-bead test, hemispherical stretching, the strip-reduction test, the bending under tension (BUT) test, and the strip-tension test (STT).

In the last decades, the $90^{\circ}$ bend test or draw-bend formability test has gained great prominence in the tribological studies of SMF processes. Owing to the dual displacement control of the grips on some equipment, it is possible to perform more than one formability test, such as the BUT test, STT, draw-bend springback (DBS) test, and draw-bend fracture (DBF) test ${ }^{13-26}$. This type of tribo-simulator can simulate the contact conditions present in the region of the die radius and punch of deep drawing processes with good accuracy; therefore, the results can be used as input data in numerical simulation software to improve the pre-production accuracy of the pieces, and consequently, improve productivity and product quality. The characterization of lubricants ${ }^{27,28}$ and coatings $^{29}$ and the inadequate processing of materials can also be investigated with this type of tribo-simulator.

Based on these arguments, a tribo-simulator based on a $90^{\circ}$ bend test system with double-displacement control of the grips was designed to investigate the effect of different contact conditions or formability tests (BUT test and STT) on the tribological behavior of AISI 304 and AISI 430 stainlesssteel sheets. The effects of the texture and microstructure of the sheets on the measured coefficients of friction (COFs) and changes that occurred on the tribosurfaces also were investigated.

\section{Theoretical Considerations of the Preliminary Design}

Generally, the design of a tribo-simulator is multidisciplinary and combines concepts from various areas of science, such as mechanics, hydraulics, electrical systems, electronics, automation, and computing. Furthermore, it involves several manufacturing phases. Figure 1 shows a diagram of the phases adopted in the preliminary design of the tribo-simulator used in the present work.

Figures 2 and 3 show the 3D design and a schematic of the data acquisition system (DAS) of the tribo-simulator, respectively. As shown in Figure 2, this equipment has an independent structure and application of force via a hydraulic system. Two hydraulic cylinders are oriented at $90^{\circ}$ to each other and installed on a metallic structure at the intersection of their lines of action. At this intersection, there is a pin or roller that represents the radius of the bending tool or drawing die with two hydraulic cylinders individually providing a restraining force (or back force) and a tensile force (or front force). When the metal strip slides over the tool, it is subjected to tensile, flexure, bending, and unbending loads, making it possible to simulate the friction between the tribosurfaces. As shown in Figure 3, the DAS is used to simultaneously measure the acting forces $\left(F_{1}\right.$ and $F_{2}$ ), friction-induced torque $(T)$, and displacement $(U)$ of both hydraulic actuators. The total dimensions of the tribo-simulator (length, height, and width) are $1880 \times 1640 \times 787 \mathrm{~mm}$. Table 1 lists the operational range of the parameters adopted in the preliminary design.

\section{Materials and Methods}

Table 2 shows the list of materials and the total cost of each phase of the tribo-simulator design. The materials used to investigate the tribological behavior under different contact conditions were AISI 304 and AISI 430 stainless-steel sheets, both with a thickness of $0.8 \mathrm{~mm}$ and received under the following conditions: cold rolled, annealed, and pickled, followed by a slight rolling pass and surface hardening (skin pass). The chemical compositions of the steel sheets are listed in Table 3.

Tensile tests were performed to determine the mechanical properties of the steel sheets using a universal testing machine (Emic DL30000) with a capacity of up to $300 \mathrm{kN}$. Three samples in different direction $\left(0^{\circ}, 45^{\circ}\right.$, and $\left.90^{\circ}\right)$ relative to the rolling direction were manufactured according to ASTM E8/E8M-16 $\mathrm{a}^{30}$ using wire electrical discharge machining (Eurostec EURO-FW1). Their mechanical properties are listed in Table 4 . The $n, R, \bar{R}$, and $\Delta R$ coefficients were determined according to the procedures described by Banabic et al. ${ }^{31}$.

The bending pins were of DIN X100CrMoV8-1-1 steel and fabricated by turning and milling. To increase the hardness and wear resistance, the pins were subjected to a

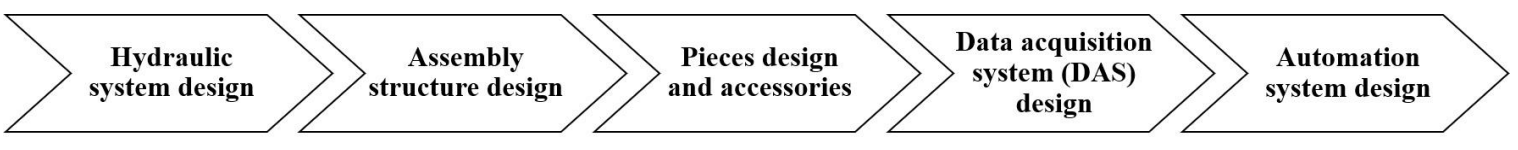

Figure 1. Phases diagram adopted in the tribo-simulator design. Reference: Paper authors. 


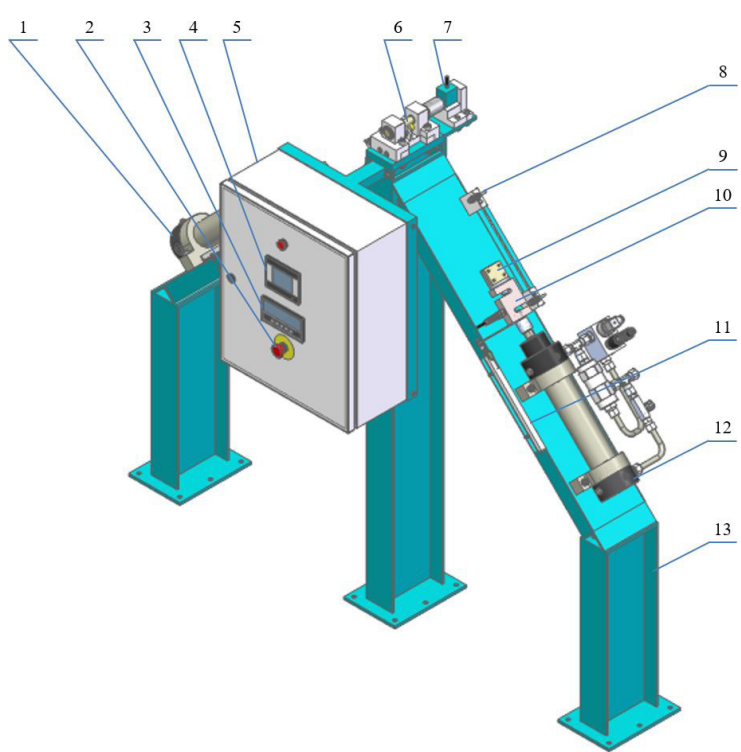

Figure 2. 3D design of the tribo-simulator: (1) Front hydraulic cylinder, (2) emergency button, (3) torque meter, (4) human-machine interface (HMI), (5) control panel, (6) roller, (7) torque sensor, (8) inductive proximity sensor, (9) grip, (10) load cell, (11) LVDT position sensor, (12) back hydraulic cylinder, and (13) assembly structure. Reference: Paper authors.

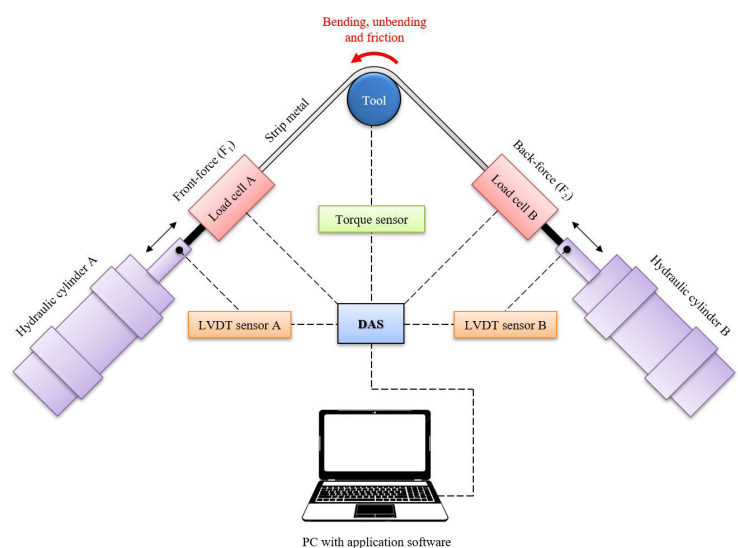

Figure 3. Schematic representation of the DAS. Reference: Paper authors. quenching heat treatment at $1080^{\circ} \mathrm{C}$ (solubilized for $30 \mathrm{~min}$ ) with natural cooling to room temperature $\left(\sim 30^{\circ} \mathrm{C}\right)$, followed by double tempering at $525^{\circ} \mathrm{C}$ for $2 \mathrm{~h}$ and cooling in open air. Finally, the bending pins were polished with a series of emery papers from 200 to 1200 grit to eliminate machining marks. The surface roughness values of the materials used in the formability tests were determined using a portable roughness tester (Tesa Rugosurf 20). At least five roughness measurements were taken along lines that were $16 \mathrm{~mm}$ long, and the average values are shown in Table 5. For each test, the bending pin roughness parameters were monitored, if necessary, the bending pins were rotated to provide a new wear-free contact surface for the subsequent tests.

To compare the tribological behavior of the stainlesssteel sheets under different contact conditions, the designed tribo-simulator was used to conduct two formability or friction tests that simulate the contact conditions present in the region of the radii in deep drawing processes (Figure 4a): the BUT test and STT. As described by Folle and Schaeffer ${ }^{18}$, the BUT test (Figure 4b) consists of bending and sliding a strip $(t)$ around the radius $(R)$ of a tool or bending pin, which simulates the contact condition between the blank and die radius. A force is applied at one end of the strip (frontal force, $\left.F_{1}\right)$ to generate movement relative to the bending pin, while at the other end of the strip, a force contrary to its movement (back force, $F_{2}$ ) is applied to generate tension. In contrast, in the STT (Figure 4c), one side of the strip moves at a constant speed $\left(F_{1}\right)$, while the other end remains fixed $\left(F_{2}\right)$, as described by Sniekers ${ }^{22}$. This test simulates the contact condition between the blank and punch radius. The angle between the acting forces is called the bending angle, in this case is $90^{\circ}$.

The force required to pull the strip ( $\left.F_{1}\right)$ must overcome the three basic forces shown in the total forces balance in Equation $1^{13}$ :

$$
F_{1}=F_{2}+F_{f}+F_{b}
$$

where $F_{2}$ is the back force, $F_{f}$ is the frictional force at the contact interface, and $F_{b}$ is the force necessary to bend the strip around the tool radius. $F_{b}$ can be calculated as the difference between the front force $\left(F_{1}^{*}\right)$ and the back force

Table 1. Operational parameters adopted on tribo-simulator design.

\begin{tabular}{ccc}
\hline Initials & Operational parameters & Description \\
\hline$F_{1} e F_{2}$ & Applied forces (max.) & $44.5 \mathrm{kN}$ \\
\hline$T$ & Torque at the bending pin (max.) & $50 \mathrm{Nm}$ \\
\hline$l$ & Metal strip length & 530 to $770 \mathrm{~mm}$ \\
\hline$w$ & Metal strip width & 25 to $30 \mathrm{~mm}$ \\
\hline$R$ & Bending pin radius & $6.5 \mathrm{~mm}$ \\
\hline$\theta$ & Bending angle & $90^{\circ}$ \\
\hline$V_{1} e V_{2}$ & Drawing speed (max.)* & $73 \mathrm{~mm} / \mathrm{s}^{*}$ \\
\hline$P$ & Hydraulic unit pressure (max.) & $250 \mathrm{bar}$ \\
\hline$W$ & Electric motor power & $10 \mathrm{HP}$ \\
\hline$Q$ & Pumps flow & $1.41 \mathrm{pm}$ and $14 \mathrm{lpm}$ \\
\hline$C$ & Reservoir capacity (max.) & $50 \mathrm{lt}$ \\
\hline$d_{1}$ & Piston diameter & $63 \mathrm{~mm}$ \\
\hline$d_{2}$ & Piston rod diameter & $25.4 \mathrm{~mm}$ \\
\hline$h$ & Cylinder displacement (max.) & $250 \mathrm{~mm}$ \\
\hline
\end{tabular}

\footnotetext{
*the speed of the hydraulic actuators is adjusted using in-line flow valves. Reference: Paper authors.
} 
Table 2. List of materials and total cost of the tribo-simulator design.

\begin{tabular}{|c|c|c|}
\hline Design phases & List of materials & Cost \\
\hline $\begin{array}{l}\text { Hydraulic } \\
\text { system }\end{array}$ & Hydraulic unit, hydraulic cylinders, and filtered oil & USD 6247.13 \\
\hline $\begin{array}{l}\text { Assembly } \\
\text { structure }\end{array}$ & $\begin{array}{l}\text { Central column and side support bases (I-profile), support bases of the hydraulic cylinders } \\
\text { (laminated steel U-profile), and support bases of the displacement and proximity sensors } \\
\text { (L-profile) }\end{array}$ & USD 478.11 \\
\hline $\begin{array}{l}\text { Pieces and } \\
\text { accessories }\end{array}$ & Die and bending pins, grip claws, and assembly accessories of the torque sensor & USD 318.11 \\
\hline $\begin{array}{l}\text { Data } \\
\text { acquisition } \\
\text { system (DAS) }\end{array}$ & $\begin{array}{l}\text { Load cell (RAS1-10KS-S, } 44.5 \mathrm{kN} \text {, and } 0.02 \% \text { precision), LVDT sensors (KTM series, } 275 \\
\text { mm, accuracy of } 0.05 \%) \text {, torque sensor (ZHKY } 8050 \mathrm{~A}, 50 \mathrm{Nm}, 0.1 \% \text { accuracy), torque meter } \\
\text { (PY801, 0.2\% accuracy), resistive interfaces }(0.02 \% \text { accuracy, } 24-\text { bit analog-digital converter, } \\
500 \mathrm{~Hz} \text { ), and application software (SensorVUE, Loadstar Sensors) }\end{array}$ & USD 8669.17 \\
\hline $\begin{array}{l}\text { Automation } \\
\text { system }\end{array}$ & $\begin{array}{l}\text { Standard box with electrical parts and devices (circuit breaker, connection terminals, relays, } \\
\text { power supply, etc.), programmable logic controller (PLC) (Delta 20SX2), human-machine } \\
\text { interface (HMI) (Delta 4.3” DOP-B03S211), and operational software development }\end{array}$ & USD 3098.68 \\
\hline Total cost & & USD $18,811.20$ \\
\hline
\end{tabular}

Table 3. Chemical compositions of the AISI 304 and AISI 430 stainless-steel sheets (wt. \%).

\begin{tabular}{ccccccccc}
\hline Material & $\mathrm{C}$ & $\mathrm{Mn}$ & $\mathrm{Si}$ & $\mathrm{Cr}$ & $\mathrm{Ni}$ & $\mathrm{Mo}$ & $\mathrm{Nb}$ & $\mathrm{N}(\mathrm{ppm})$ \\
\hline AISI 304 & 0.0218 & 1.0579 & 0.2689 & 18.2293 & 8.1220 & 0.0831 & 0.0042 & 206 \\
\hline AISI 430 & 0.0164 & 0.2454 & 0.2447 & 16.4810 & 0.2964 & 0.0234 & 0.3384 & 231 \\
\hline
\end{tabular}

Reference: Paper authors.

Table 4. Mechanical properties of the AISI 304 and AISI 430 stainless-steel sheets.

\begin{tabular}{|c|c|c|c|c|c|c|c|c|c|}
\hline Material & $\begin{array}{c}\text { Sample } \\
\text { direction }\end{array}$ & $S_{y}(\mathrm{MPa})$ & $S_{u}(\mathrm{MPa})$ & $e_{u}(\%)$ & $e_{t}(\%)$ & $n$ & $R$ & $\bar{R}$ & $\Delta R$ \\
\hline \multirow{3}{*}{ AISI 304} & $0^{\circ}$ & 276.8 & 605.2 & 64.2 & 70.7 & 0.433 & 0.876 & \multirow{3}{*}{1.076} & \multirow{3}{*}{-0.393} \\
\hline & $45^{\circ}$ & 276.6 & 590.0 & 63.9 & 71.3 & 0.422 & 1.272 & & \\
\hline & $90^{\circ}$ & 281.2 & 603.8 & 63.7 & 71.2 & 0.434 & 0.882 & & \\
\hline \multirow{3}{*}{ AISI 430} & $0^{\circ}$ & 316.1 & 464.9 & 22.3 & 32.7 & 0.205 & 1.419 & \multirow{3}{*}{1.366} & \multirow{3}{*}{0.340} \\
\hline & $45^{\circ}$ & 343.4 & 475.6 & 17.9 & 27.2 & 0.188 & 1.196 & & \\
\hline & $90^{\circ}$ & 317.5 & 466.5 & 19.8 & 33.2 & 0.201 & 1.654 & & \\
\hline
\end{tabular}

$S_{y}$ = yield strength; $S_{u}=$ ultimate tensile strength; $e_{u}=$ uniform elongation; $e_{t}=$ total elongation; $n=$ coefficient of hardening; $R=$ normal anisotropy coefficient; $\bar{R}=$ mean normal anisotropy coefficient; $\Delta R=$ planar anisotropy coefficient. Reference: Paper authors. Analysis performed during this research.

Table 5. Surface roughness parameters of the materials used in the tribological tests.

\begin{tabular}{ccccc}
\hline \multirow{2}{*}{ Material } & $R_{a}$ & \multicolumn{4}{c}{ Surface roughness parameters $(\mu \mathrm{m})$} \\
\cline { 2 - 5 } & $0.071 \pm 0.006$ & $0.077 \pm 0.012$ & $R_{z}$ & $0.902 \pm 0.119$ \\
\hline AISI 304 & $0.048 \pm 0.007$ & $0.068 \pm 0.015$ & $0.691 \pm 0.273$ & $1.217 \pm 0.203$ \\
\hline AISI 430 & $0.539 \pm 0.025$ & $0.737 \pm 0.044$ & $4.527 \pm 0.396$ & $6.175 \pm 0.836$ \\
\hline Bending pins* & &
\end{tabular}

*two bending pins were manufactured and the values listed refers to the average of their roughness parameters. $R_{a}=$ average roughness, $R_{a}=$ root mean square roughness parameter, $R_{z}=$ zero-point peak-valley surface roughness, $R_{t}=$ total height. Reference: Paper authors. Analysis performed during this research.

$\left(F_{2}^{*}\right)$ during the friction test with the pin free $9,13,18$; that is, the bending pin can revolve freely around its axis of symmetry.

As noted by Andreasen et al. ${ }^{32}$, the friction model present in Equation 2 has been commonly used to describe the frictional condition in SMF processes and is known as Coulomb's friction model. Furthermore, this friction model was derived from a single experiment and uses the relationship between the shear stress $(\tau)$ (Equation 3 ) and contact pressure $(p)$ (Equation 4$)$ to calculate the $\mathrm{COF}^{18}$.

$$
\begin{aligned}
\mu & =\frac{\tau}{p}=\frac{4 T}{\pi R\left(F_{1}+F_{2}\right)} \\
\tau & =\frac{2 T}{\pi W R^{2}} \\
p & =\frac{F_{1}+F_{2}}{2 W R}
\end{aligned}
$$

where $T$ is the friction-induced torque, $R$ is the bending pin radius, and $W$ is the strip width. 


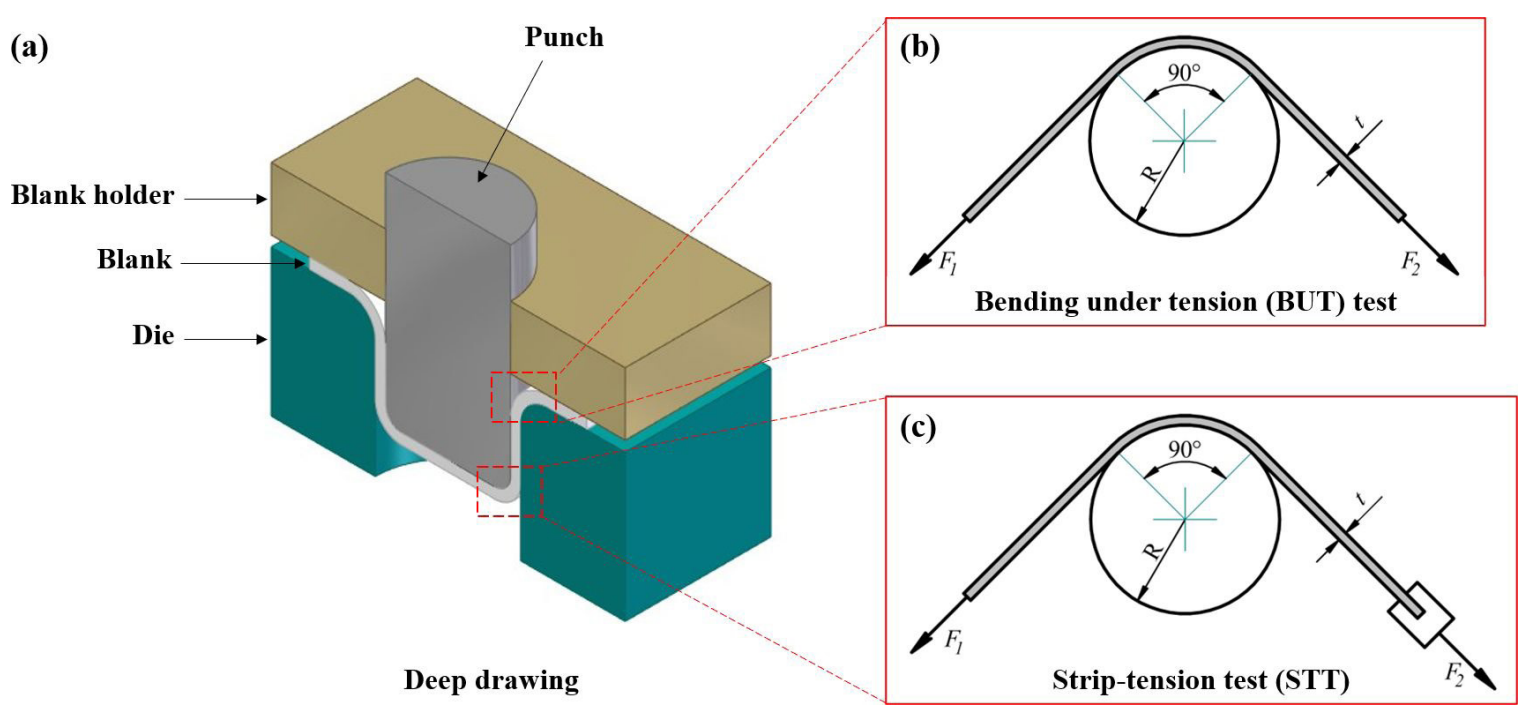

Figure 4. (a) Schematic representation of the deep drawing process, (b) BUT test, and (c) STT. Reference: Paper authors.

The operational parameters adopted in the formability tests illustrated in Figures $3 \mathrm{~b}$ and $\mathrm{c}$ are listed in Table 6. The lubricant used in this study was a typical mineral-based cold-forming oil with a kinematic viscosity of $120 \mathrm{mPa} . \mathrm{s}$ and a specific gravity of 0.894 . For each test, the contact surfaces of the samples were cleaned using acetone, and then the lubricant was applied in abundance using a silicone oil brush.

The surfaces of the samples were observed by scanning electron microscopy (SEM) (Jeol JSM-6510 LV) using an acceleration voltage of $20.0 \mathrm{kV}$. Metallographic examinations were conducted by conventional optical microscopy (OM) (Leica DMRM equipped with the image analysis software OmniMet). For OM observation, FSS samples were subjected to mechanical polishing process and etched with Vilella reagent (950 $\mathrm{mL} \mathrm{C}_{2} \mathrm{H}_{6} \mathrm{O}, 10 \mathrm{~g} \mathrm{C}_{6} \mathrm{H}_{3} \mathrm{~N}_{3} \mathrm{O}_{7}$, and $\left.50 \mathrm{~mL} \mathrm{HCl}\right)$. However, ASS samples were subjected to electrochemical polishing (EP) process (Struers LectroPol-5) and etched with Beraha reagent ( $100 \mathrm{~mL}$ stock solution: $48 \mathrm{~g} \mathrm{NH}_{4} \mathrm{HF}_{2}, 800 \mathrm{~mL}$ distilled water, and $400 \mathrm{~mL} \mathrm{HCl}$; plus $1 \mathrm{~g} \mathrm{KHSO}_{3}$ ). The phases in the AISI 304 steel samples were identified by X-ray diffraction (XRD) (Philips PW 1710) using $\mathrm{Cu} \mathrm{K} \alpha$ radiation in the $2 \theta$ range $30^{\circ}-120^{\circ}$ with a step of $0.02^{\circ} / \mathrm{s}$, voltage of $50 \mathrm{kV}$, and current of $35 \mathrm{~mA}$. The microhardness was measured using a Vickers microdurometer (Shimadzu HMV-2T) with a load of $4.9 \mathrm{~N}$ and a dwell time of $15 \mathrm{~s}$. The final microhardness values are the average of ten indentation measurements.

\section{Results and Discussion}

\subsection{Manufactured tribo-simulator}

As shown in Figure 5a, the tribo-simulator was successfully manufactured. The following are the significant advances and advantages of this tribo-simulator:

- Four different types of formability tests can be performed in an automated manner: BUT test, STT, DBS, and DBF.
Table 6. Operating parameters used in the formability tests.

\begin{tabular}{cc}
\hline Parameter & Description \\
\hline Specimen direction & $0^{\circ}$ and $90^{\circ}$ \\
\hline Specimen dimensions & $0.8 \times 25 \times 750 \mathrm{~mm}$ \\
\hline Speed drawing & $10 \mathrm{~mm} / \mathrm{s}$ \\
\hline Pins radius & $6.5 \mathrm{~mm}$ \\
\hline
\end{tabular}

Reference: Paper authors.

- Strips with a wide range of lengths can be tested, which significantly reduces the material loss in the experimental tests.

- The sensor and torque meter allow the COF to be calculated directly by Equation 2, which significantly reduces the test time and required number of samples.

- The inductive sensors allow the adjustment of the maximum displacement distance of the hydraulic actuators.

- The hydraulic system is equipped with two hydraulic pumps, one with low and one with high flow, allowing the tribo-simulator to be operated at different speeds, pressures, forces, and stop times.

- The total amount spent on the equipment was less than $6 \%$ of the value of an industrial equipment (market price exceeding USD $320,000^{15}$, excluding import taxes).

Figure $5 \mathrm{~b}$ shows the experimental results obtained using the tribo-simulator. In this example, the AISI 304 steel strip was subjected to the BUT test, where the acting forces $\left(F_{1}\right.$ and $\left.F_{2}\right)$ and friction-induced torque $(T)$ are plotted as a function of the test time and strip orientation relative to the rolling direction $\left(0^{\circ}\right.$ and $\left.90^{\circ}\right)$. The $0-5$ s interval is the time required to start the test after the automatic activation command on the human-machine interface (HMI) screen. According to Trzepiecinski and $\mathrm{Lemu}^{28}$, the increase in the acting forces can be attributed to strain hardening. However, the increase in frictional resistance between the strip and pin causes that $F_{1}>F_{2}$. Therefore, a greater difference between 


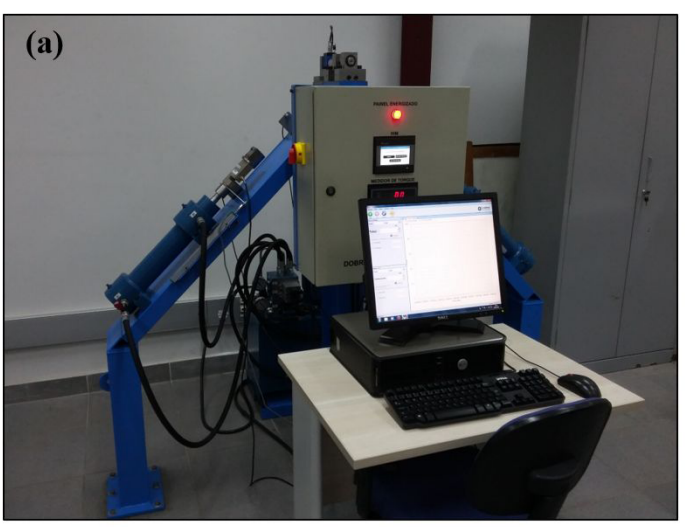

(b)

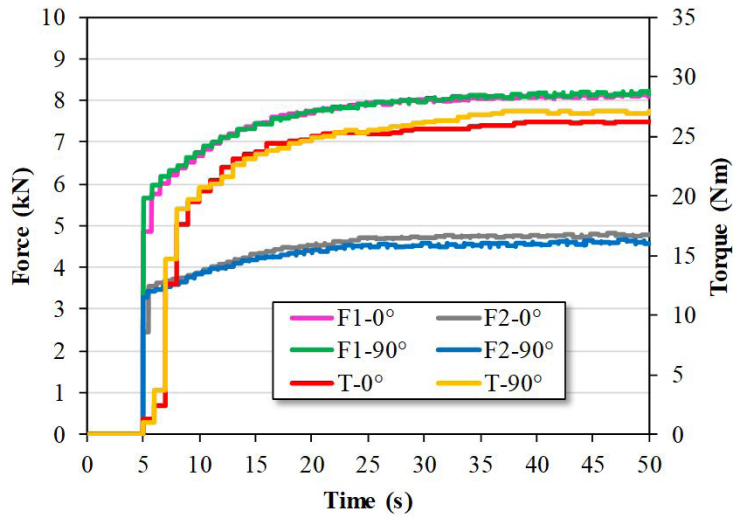

(c)

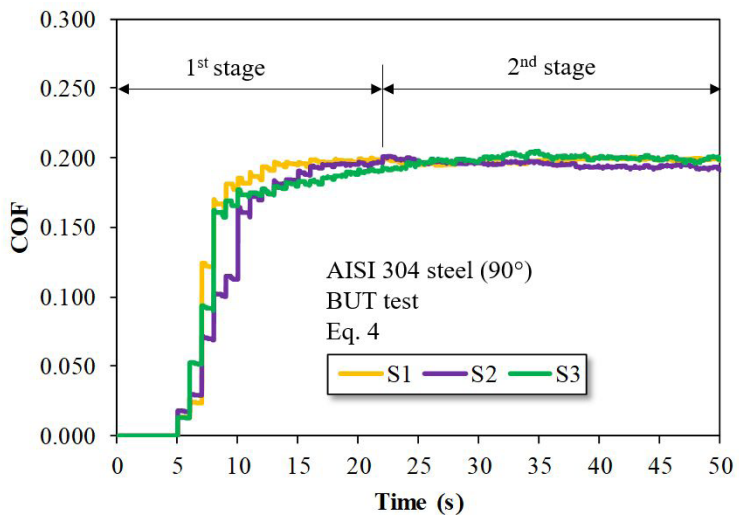

Figure 5. (a) Manufactured tribo-simulator, (b) Acting forces and torque measured in function of test time and strip orientation, and (c) Repeatability of measured COF. Reference: Paper authors. Analysis performed during this research.

the acting forces corresponds to a greater frictional force $\left(F_{f}\right)$ acting at the interface of the tribocontact. This statement is in accordance with Equation 1, where $\left(F_{1}-F_{2}\right) \propto F_{f}$ for a constant bending force $\left(F_{b}\right)$. In addition, the intensity of the acting forces was generally higher in the STT than in the BUT test for both materials. As illustrated in Figure 4c, one end of the strip remained fixed during the STT, which increased the intensity of the acting forces to generate the relative movement between the strip and pin.

The experimental results can also by analyzed using the friction-induced torque $(T)$ measured during the formability tests. As shown in Figure 5b (red and yellow lines), the measured torque exhibited the same trend as the difference between the acting forces, that is, a greater measured torque corresponded to a greater the frictional force at the interface of the tribosurfaces. In addition to allowing the direct calculation of the $\mathrm{COF}$, the torque sensor can precisely determine the breakage of the lubricant film because it is more sensitive to small changes at the tribocontact compared to the simple analysis of the acting forces.

Figure $5 \mathrm{c}$ shows the repeatability of the COF measurements with the tribo-simulator. Three identical samples of AISI 304 steel were tested under the same process conditions (BUT test, $R=6.5 \mathrm{~mm}, V_{1}=10 \mathrm{~mm} / \mathrm{s}$, and lubricated). Two different stages were observed in the friction curves during the formability tests. The increase in the COF at the beginning of the test (first stage) is typically attributed to the accommodation of contact surfaces before reaching a stable stage (second stage) exhibited by linear friction conditions ${ }^{28}$. In this example, the COF was determined using Equation 2 in the stable range of the test (second stage); the average COF was approximately 0.196 with a standard deviation of 0.02 , indicating that the repeatability of measurements was satisfactory.

\subsection{Analysis of the COFs}

Figure 6 shows the COFs of the stainless-steel sheets measured using the manufactured tribo-simulator. The results are plotted as a function of material (AISI 304 and AISI 430 steels), test type (BUT test and STT), and strip orientation $\left(0^{\circ}\right.$ and $\left.90^{\circ}\right)$. The differences in the results were identified, and the effects of the formability test, sheet texture, and sheet microstructure on the COF are discussed in the following sections.

\subsubsection{Effect of the BUT test}

The results indicate that the COFs measured from the BUT test for AISI 430 steel were, on average, approximately 33\% higher than those obtained for the AISI 304 steel. According to Kim et al. ${ }^{33}$, bending the strip over the pin during the BUT test creates a condition close to the plane-strain condition, even though the width is narrow compared to the length. 
As shown in Table 4, the AISI 430 steel exhibited greater property heterogeneity compared to the AISI 304 steel. As a result, the mean normal anisotropy coefficient $(\bar{R})$ was also greater $(\sim 21 \%)$, increasing its resistance to necking and, consequently, its plane-strain capacity. Trzepiecinski ${ }^{21}$ and Masters et al. ${ }^{34}$ demonstrated that the COF increases with increasing plastic deformation under dry and lubricated contact conditions owing to the roughening of the strip by plastic deformation. This roughening is associated with deformation bands that develop on the sheet surface. Figure $7 \mathrm{~b}$ shows the effect of plastic deformation on the topographic surface of the strip subjected to BUT test compared to undeformed strip (Figure 7a), i.e., as-received. Deformation bands aligned within a short range, and microvoids were identified at the strip surface. This behavior was observed for both materials and in both formability tests, albeit at different intensities.

Garrison and Moody ${ }^{35}$ discussed a theory of ductile fracture in metals that explains the generation of aligned deformation bands. They believed that these lines of deformation are potential regions for void nucleation and fracture. Under these

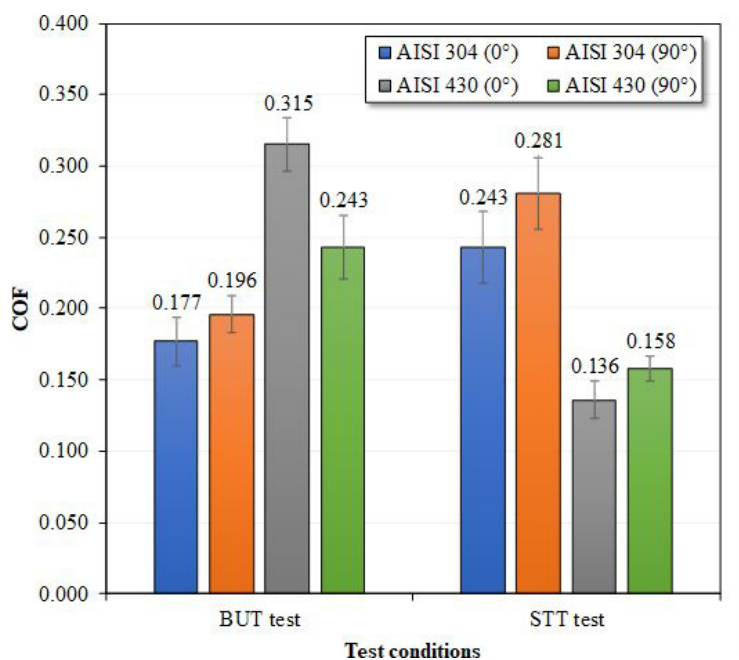

Figure 6. COFs plotted in function of the material, formability test, and strip orientation. Reference: Paper authors. Analysis performed during this research. conditions, the frictional resistance increases owing to the greater interaction between the asperities of the tribosurfaces. Therefore, it can be concluded that the increase in the COF for the AISI 430 steel in the BUT test was due to its higher plane-strain capacity. It is probable that debris arising from the greatest relative movement between the sheet and tool aggravated the adhesive and abrasive wear processes during tribocontact, further increasing the $\mathrm{COF}$.

Bhushan ${ }^{36}$ explained that relative sliding introduces a frictional (tangential) force at the interface of the tribocontact, and as the magnitude of the shear stress increases, the COF also increases. Generally, in SMF processes, this tangential force is the result of the combined effect of plastic deformation and sliding of the strip over the tool. Under these conditions, the soft asperities on the strip undergo plastic deformation or flattening, and as a result, the real contact area and frictional resistance tend to increase. The real contact area depends on factors such as the roughness parameters, normal force between the tribological pair due to deformation, geometry of the contact surface, and material properties. This last item is associated with the hardening capacity of the material asperities and has a strong influence on the tribological behavior $^{21}$. Therefore, steel sheet asperities with a greater hardening capacity are flattened less by the hard asperities of the tool. Thus, the valleys can store more lubricant, which reduces friction. As shown in Table 4, the AISI 304 steel exhibited a coefficient of hardening $(n)$ considerably higher ( $\sim 54 \%$ ) than that of the AISI 430 steel, which may have provided more effective lubrication during the BUT test, decreasing the COF.

The difference between the initial surface roughness values (Ra) also may be contributed to the lower COF of the AISI 304 steel in the BUT test because its initial roughness was, on average, approximately $48 \%$ higher than that of the AISI 430 steel (Table 5). Evin et al. ${ }^{6}$ explained that on a very smooth surface, the lubricant is not well-retained on the contact surfaces during the drawing of the strip. As a result, cold welds form between the sheet surface and the tool even at low pressures and short paths of drawing. According to Trzepiecinski and Lemu ${ }^{28}$, a rougher surface can retain more lubricant in the valleys of its asperities; therefore, the lubrication at the contact interface is more efficient,

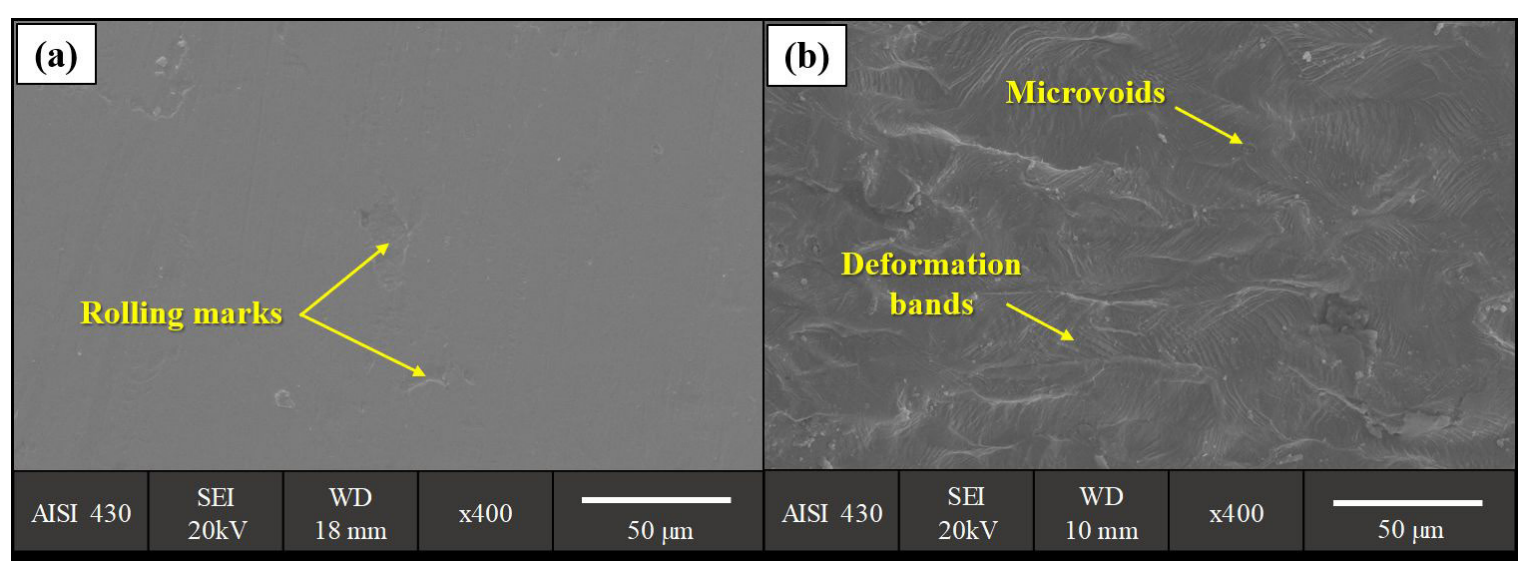

Figure 7. SEM images of topographic surface of the AISI 430 steel strip under different test conditions. (a) undeformed and (b) BUT test. Reference: Paper authors. Analysis performed during this research. 
decreasing the frictional resistance. However, according to the authors, this is only true to a certain point because the balance between the adhesion and plastic deformation mechanisms controls friction and wear during tribocontact.

\subsubsection{Effect of the STT test}

As shown in Figure 6, the steel sheets exhibited different behaviors during the STT: the COFs obtained for the AISI 304 steel strip were, on average, approximately $44 \%$ higher than those obtained for the AISI 430 steel strip. This behavior can be attributed to the mutual effect of two main factors: the deformation mode and sheet ductility.

As illustrated in Figure 4c, stretching deformation was predominant in the STT. After uniform elongation was achieved and necking began, plastic deformation was located in the thickness, while the plane and width of the specimen were no longer subject to plastic deformation. As shown in Table 4, the AISI 304 steel exhibited a substantially higher uniform elongation ( $\sim 69 \%$ ) compared to that of the AISI 430 steel; that is, until necking began, the AISI 304 steel exhibited a greater amount of plastic deformation and sliding over the tool. Under these conditions, the relative movement between the sheet and tool was generally more severe for the AISI 304 steel than that for the AISI 430 steel. As discussed previously, the strip roughness increased with increasing plastic deformation, and the magnitude of the shear stress increased with increasing sliding; consequently, the frictional resistance also increased.

Note that, as shown in Figure 6, the AISI 304 steel exhibited a higher COF ( 29\%) in the STT compared to that obtained in the BUT test, while for the AISI 430 steel, the COF was lower in the STT $(\sim 47 \%)$. The probable causes of these different behaviors are discussed in the following sections.

\subsubsection{Effect of texture}

The results shown in Figure 6 suggest that the texture directionality strongly influenced the tribological behavior of both steel sheets in the formability tests, which can be attributed to the anisotropy of the steel sheets. Banabic et al. ${ }^{31}$ explained that owing to their crystallographic structure and the characteristics of the rolling process, steel sheets generally exhibit significant anisotropy in the mechanical properties. The variation in their plastic behavior with direction is assessed by Lankford parameter or normal anisotropy coefficient $(R)$. The greater the $R$ value, the more anisotropic is the material. Therefore, as shown in Table 4, the AISI 430 steel was more anisotropic than the AISI 304 steel.

For the AISI 304 steel strips subjected to the BUT test and STT, the COFs obtained in the direction perpendicular to rolling $\left(90^{\circ}\right)$ were, on average, approximately $10 \%$ and $14 \%$ higher than those obtained in the rolling direction $\left(0^{\circ}\right)$, respectively. This behavior can be attributed to the greater $R$ value exhibited by the AISI 304 steel in this direction because the surface roughness tends to increase with increasing amount of plastic deformation. As discussed previously, the interaction between the tribocontact asperities and frictional resistance increase with increasing surface roughness. In the STT, the AISI 430 steel strip also exhibited a greater COF $(\sim 14 \%)$ in the $90^{\circ}$ direction for the same reasons. However, as shown in Figure 6, the COF behaved differently for the
AISI 430 steel strip subjected to the BUT test. Although the steel sheet exhibited a greater $R$ value in the $90^{\circ}$ direction, the COF was, on average, approximately $23 \%$ higher in the $0^{\circ}$ direction. Ferrarini ${ }^{37}$ investigated the tribological behavior of the same steel sheets in the BUT test and found similar results. The probable cause of this behavior is a defect called roping or ridging.

Shin et al. ${ }^{38}$ noted that FSS sheets exhibit ridging parallel to the rolling direction when subjected to stretching or deep drawing. Over the years, various mechanisms have been proposed to explain ridging, but there is still no definitive consensus on this topic. Oliveira et al.$^{39}$ emphasized that for all hypotheses, ridging is related to the plastic anisotropy of the body-centered cubic structure and the heterogeneity of the steel sheet texture. When pulled or deep drawn, this steel shows undulations, with peaks on one side of the sheet coinciding with valleys on the other side, without a change in the thickness. The ridges have a depth in the range 20-50 $\mu \mathrm{m}$, which increases manufacturing costs owing to the required sanding and polishing operations ${ }^{38,39}$. Although the ridges are considered superficial defects that negatively affect the visual aspect of parts, the depth and width of the ridges are relevant for thin sheets because they can cause not only an increase in frictional resistance but also poor lubrication and a heterogeneous distribution of the deformation on the tool surface in the presence of large stress gradients.

Kodukula et al..$^{40}$ quantified the ridging phenomenon in FSS sheets and demonstrated that the intensity of ridges increases with increasing elongation. In this context, Figure 8 shows that the ridges formed during the BUT test were deeper and wider than those formed during the STT. In support of this statement, the strip surface roughness values $(\mathrm{Ra})$ after the BUT test and STT were approximately $4.275 \pm 0.198 \mu \mathrm{m}$ and $1.457 \pm 0.164 \mu \mathrm{m}$, respectively, which also explains the greater COF exhibited by the AISI 430 steel strip during the BUT test, as shown in Figure 6.

\subsubsection{Effect of microstructure}

Figure 9 shows OM images of the microstructures of the steel sheets. The AISI 430 steel sample is predominantly

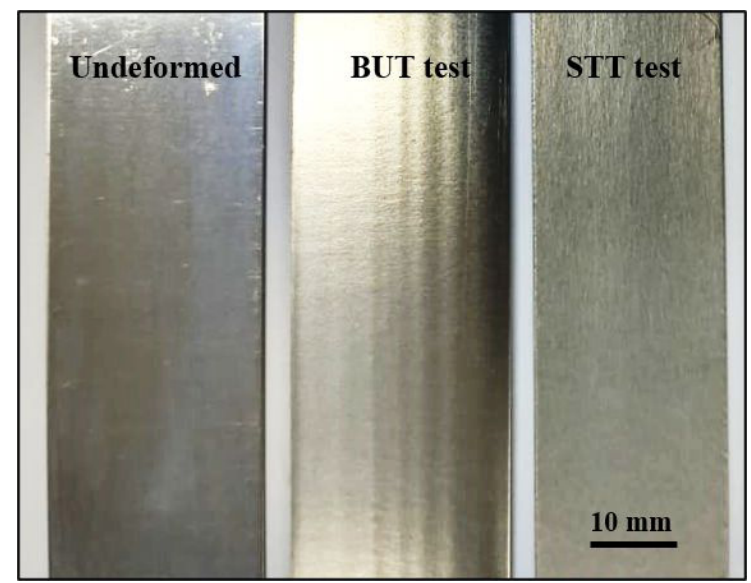

Figure 8. Typical ridges in the surface of the AISI 430 steel strip under different test conditions. Reference: Paper authors. Analysis performed during this research. 


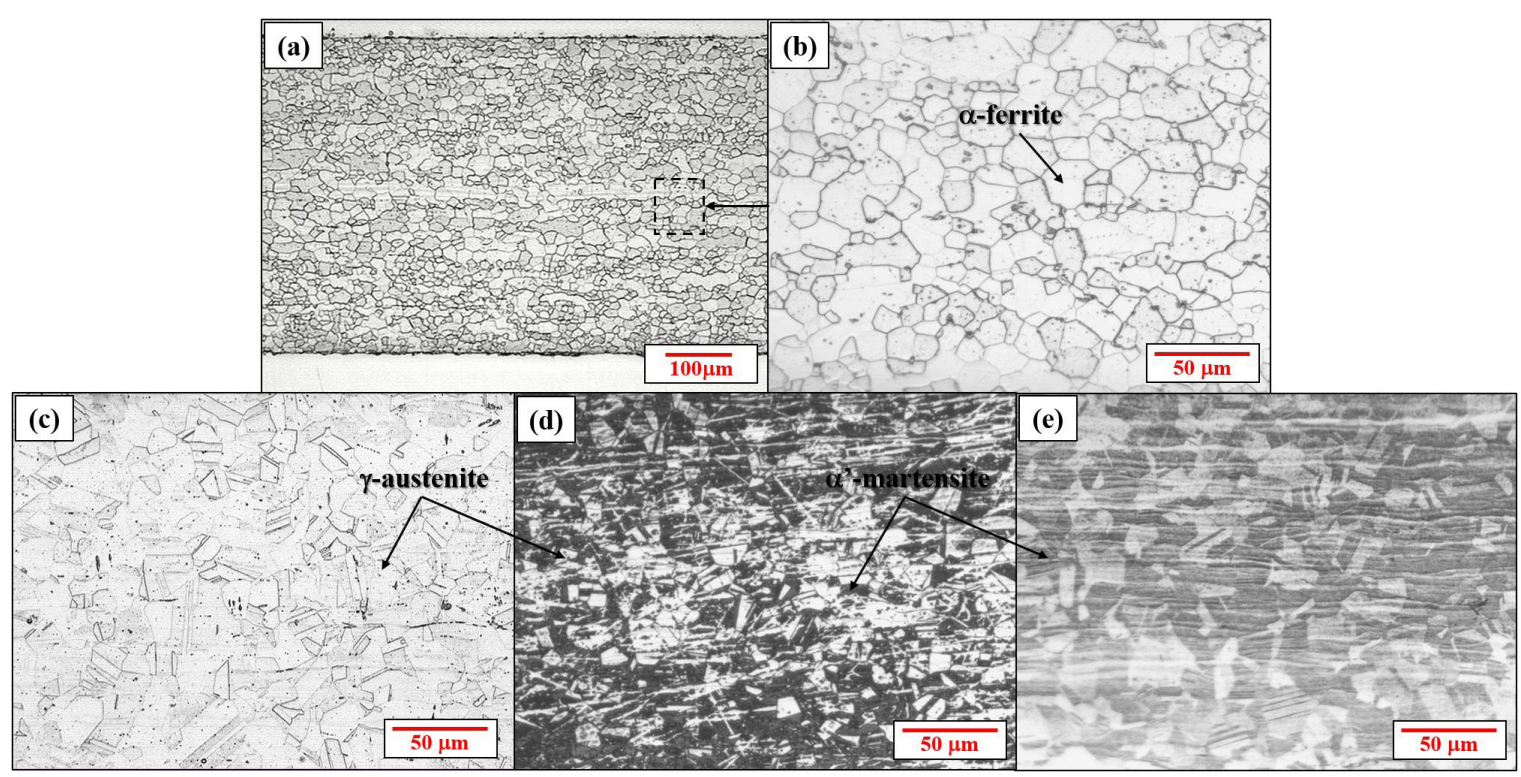

Figure 9. Microstructure of the stainless-steel sheets. (a) and (b) AISI 430 steel; (c), (d), and (e) AISI 304 steel under conditions undeformed, BUT test, and STT, respectively. Reference: Paper authors. Analysis performed during this research.

composed of a ferritic matrix (Figure 9b), and the grains were larger in the central region and smaller near-surface of the sheet (Figure 9a), because in this region the material is more shear-deformed due to the contact with the cylinder during the rolling process. Generally, this structure has cold work hardening characteristics. In contrast, the AISI 304 steel sample had a typical austenitic matrix (Figure 9c), and after the formability tests its microstructure (Figure $9 \mathrm{~d}$ and e) exhibited two different phases, $\gamma$-austenite and $\alpha$ '-martensite, indicating that a phase transformation occurred during the plastic deformation process.

According to Bleck et al. ${ }^{41}$, ASS sheets are metastable because the $\gamma$ phase can transform into martensite through the transformation induced plasticity (TRIP) effect, with the type ( $\varepsilon$ or $\left.\alpha^{\prime}\right)$ and intensity dependent on the specific material properties and test conditions. Figure 10 shows the XRD patterns of the samples subjected to different test conditions (undeformed, BUT test, and STT). Only $\gamma$-austenite and $\alpha^{\prime}$-martensite phases can be identified in the three diffractograms, and there are no peaks indicating the presence of $\varepsilon$-martensite, probably because the large amount of plastic deformation completed the sequential $\gamma \rightarrow$ $\varepsilon \rightarrow \alpha^{\prime}$ martensitic transformation in both formability tests. Regarding peak intensity, the intensity of the $\alpha$ '-martensite peak increased with the severity of the formability test; that is, the $\alpha^{\prime}$-martensite peak was more intense after the BUT test than that after the STT. This difference of behavior is also supported by the comparative analysis between Figures $9 \mathrm{~d}$ and e. Several authors ${ }^{10,42,43}$ have noted that the amount of martensite depends on parameters such as the stress state, temperature, steel composition, stacking fault energy (SFE), and amount of plastic deformation. Specifically, Lischka and Oliveira ${ }^{44}$ demonstrated that the austenite transformation in $\alpha^{\prime}$-martensite in the AISI 304 steel increases with increasing equivalent deformation. Therefore,

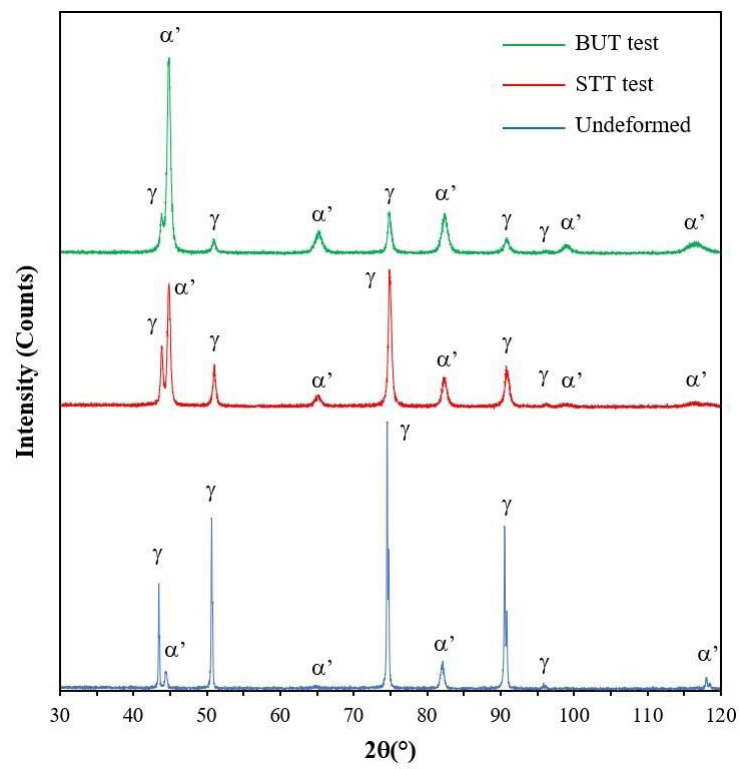

Figure 10. XRD showing the phases present in the AISI 304 steel strip under different test conditions. Reference: Paper authors. Analysis performed during this research.

in the present work, the comparative analysis confirms that the ASS samples subjected to the BUT test had a larger quantity of $\alpha$ '-martensite compared to that in the samples subjected to the STT.

Generally, martensitic structures have a high density of discordance, mechanical resistance, and hardness. The microhardness of the samples was measured and is plotted in Figure 11 as a function of the test condition. The AISI 304 steel strip subjected to the BUT test exhibited the greatest 
increase in microhardness, followed by the sample subjected to the STT. Based on these results, it can be concluded that the flattening of asperities on the AISI 304 steel strip by the hard asperities on the tool surface $(760 \pm 12 \mathrm{HV})$ was attenuated to a greater degree in the BUT test. As discussed, hard asperities store a greater amount of lubricant in the valleys of the sheet surface or "oil pockets," reducing the frictional resistance. Therefore, this behavior also explains the lower COF of the AISI 304 steel strip in the BUT test compared to that obtained in the STT. Because the AISI 430 steel strip exhibited a low hardness increase due to cold work hardening, it can be concluded that the ridging caused a more significant increase in the COF during the BUT test compared to that in the STT.

\subsection{Analysis of the tribosurfaces}

Figure 12a shows representative images of the AISI 430 steel strips subjected to different formability tests. It is possible to note discoloration and scratches in the contact

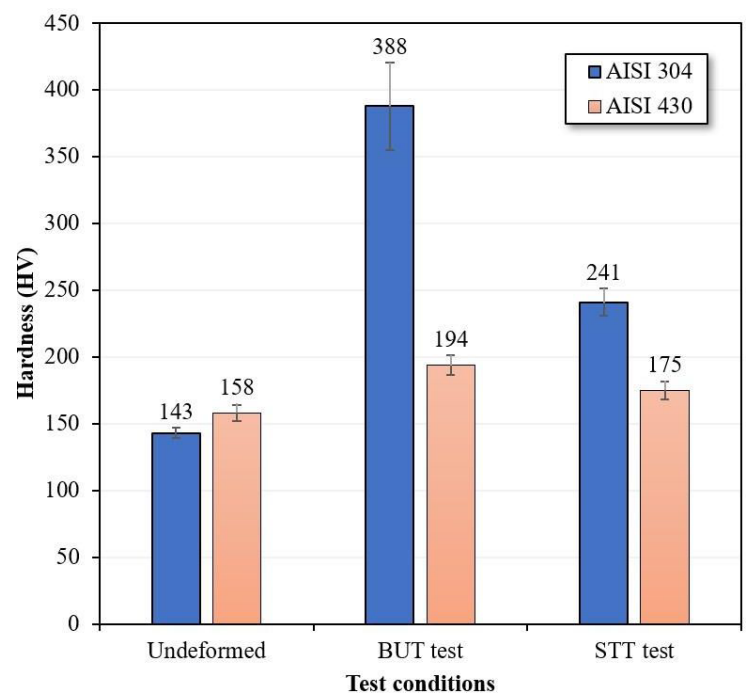

Figure 11. Microhardness plotted in function of the different test conditions and material. Reference: Paper authors. Analysis performed during this research. surface of the strips. This phenomenon is known as galling and was observed for both materials and under both test conditions. Galling is a form of severe wear caused by adhesion between sliding surfaces and should be avoided because it changes the tool geometry, increases the frictional force, causes tearing, and leads to workpiece rejection ${ }^{38,45,46}$. On the other hand, Velkavrh et al. ${ }^{47}$ noted that a measured COF can be treated with credibility only if the tribological test also provides a surface and wear microstructure similar to the pattern observed in the actual application. Therefore, the presence of galling indicates that the contact conditions present in real applications were reproduced satisfactorily in the manufactured tribo-simulator.

Comparatively, it is possible to note in Figure 12a that the galling that occurred during the BUT test was more severe than that during the STT. This behavior can be attributed to the greater severity of contact between the strip and tool, and as shown in Figure 12b, this results in increased scratching intensity and severe adhesive wear on the topographic surface of the strip. Trzepiecinski ${ }^{21}$ emphasized that kinematic differences in the mutual movement of the surfaces in contact result in different pressures. Ter Haar ${ }^{48}$ and Cora et al. ${ }^{49}$ highlighted that in the deep drawing process, the stresses are generally low $(1-10 \mathrm{MPa})$ in the region of the blank holder (Figure $4 \mathrm{c}$, STT); however, in the region of the die radius (Figure $4 b$, BUT), the stresses are considerably higher (on the order of $100 \mathrm{MPa}$ ). Blau ${ }^{50}$ noted that at higher pressures, the breakage of the lubricating film induces greater interaction between the preferential contact regions, increasing the real contact area and frictional resistance. In addition, the tool asperities being notably harder act as indenters that plow the soft surface of the sheet, aggravating the galling process. For these reasons, tribocontact in the region of the drawing die radius is generally the most severe and prone to failure compared to the other contact regions.

In addition, the combination of friction and an increase in temperature at the tribocontact may have contributed to the increase of severe adhesive wear shown in Figure 12b. This behavior can be explained by the high metallurgical compatibility between the tribological pairs because the bending pin contains some elements (e.g., $\mathrm{Cr}$ and $\mathrm{Mo}$ ) present in the stainless-steel sheets (Table 3). This high metallurgical

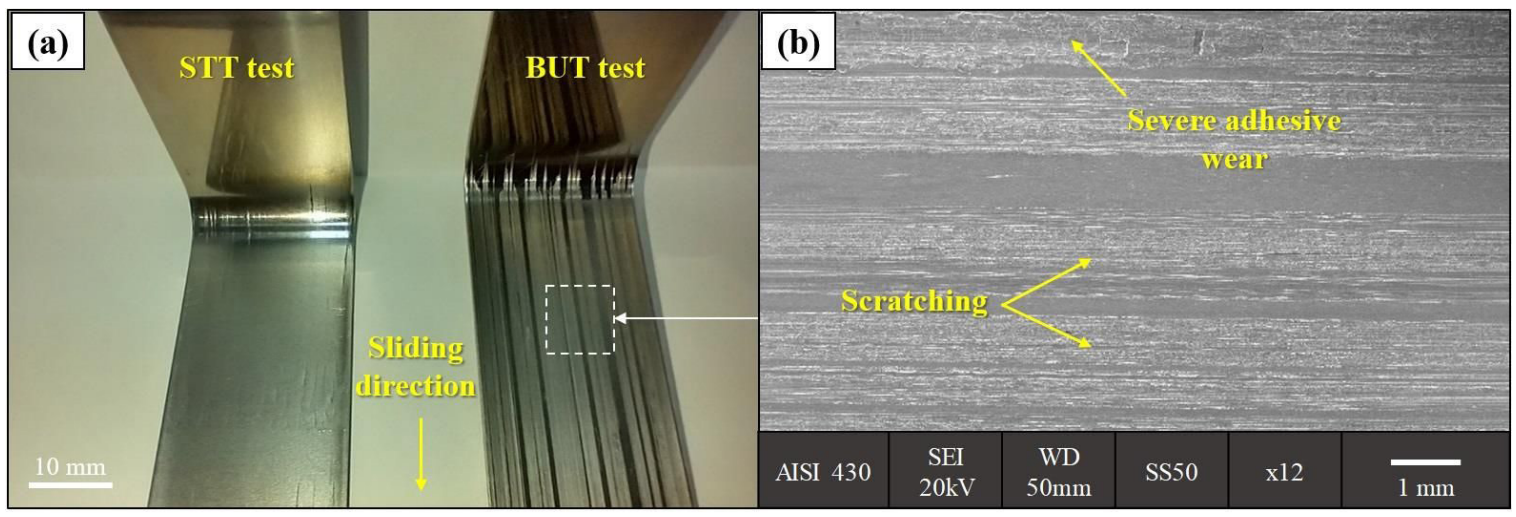

Figure 12. (a) Images of the AISI 430 steel strips subjected to different formability tests and (b) SEM image showing galling in the worn surface. Reference: Paper authors. Analysis performed during this research. 
compatibility is supported by the table of Rabinowicz ${ }^{51}$, and according to the author, metallurgically compatible metals have high friction and wear during sliding. Brushan ${ }^{36}$ also came to the same conclusion.

Figure 13 shows representative SEM images of the worn surfaces of both steel sheets subjected to the BUT test. Evidence of different micro-effects of the friction and wear mechanisms can be clearly seen, such as cracks, debris, grooves, plastic deformation, and fragments of metallic flakes indicating the occurrence of delamination or splatting. The theory of delamination introduced by $\mathrm{Suh}^{52,53}$ involves the initiation and propagation of cracks and a final fracture of the material in the region close to the surface, which explains the generation of flake-like debris. These different micro-effects were also identified on the worn surfaces of both materials subjected to the STT, but to a lower degree due to the less severe contact. As shown in Figures 13a and b, the surface of the AISI 304 steel strip presented a lower level of plastic deformation and wear compared to that of the AISI 430 steel strip (Figures 13c and d). This behavior may result from the increased microhardness of its asperities due to the TRIP effect, as shown in Figure 11.

In general, during the relative movement between strip and tool, some debris remains adhered or is friction welded to the adjacent surface. Gåård et al. ${ }^{46}$ emphasized that in SMF processes, material is generally transferred from the softer surface (metallic sheet) to the harder surface (tool). In this respect, Figure 14b shows a flake-shaped metallic fragment loosened from the strip and adhered to the bending pin surface. In real SMF processes, after intense work, the surface of the tool with adhered material will cause galling on the blanks, and the tool must be reconditioned or scrapped. For these reasons, as mentioned, the bending pins were rotated to use a contact surface without wear marks and thus not interfere in the experimental results. It is important to emphasize that the different micro-effects shown in Figure 13 do not occur in isolation but through overlapping mechanisms that are difficult to quantify and control. This overlap occurs in undetectable proportions and varies with time and the location of contact, making it almost impossible to calculate the friction and wear processes in a sliding contact. This conclusion applies to both formability tests.

As can be seen in Figure 14b, two regions of the bending pin surface (regions 1 and 2) exhibit galling. Generally, galling is oriented according to the sliding direction of the strip, that is, transversely and extends longitudinally. This behavior is due to the spikes in the pressure at the contact interface during the relative movement between the tribosurfaces and the breakage of the lubricating film. As illustrated in Figure 14a, these pressure peaks cause a

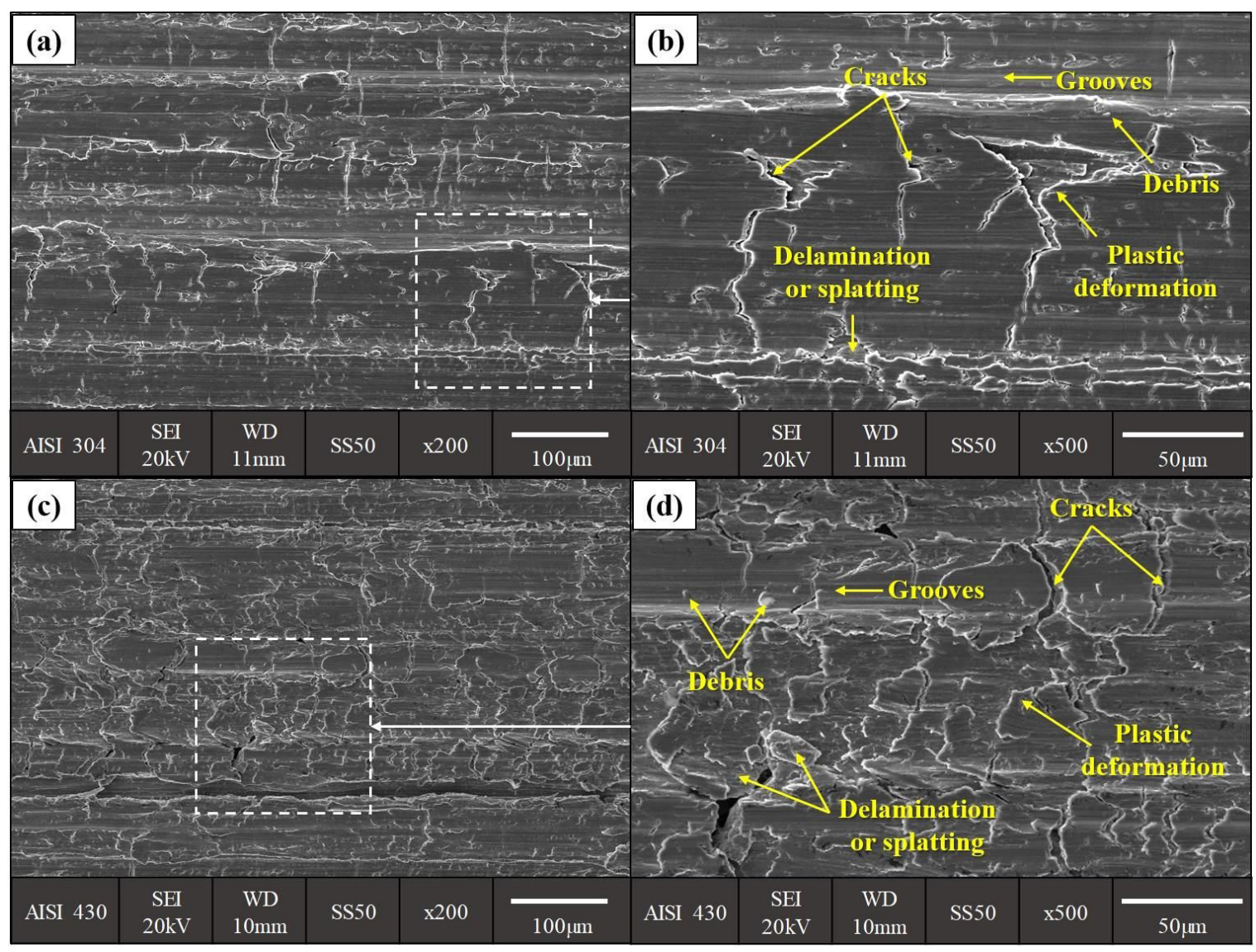

Figure 13. SEM images of the worn surface of the stainless-steel strips subjected to BUT test. (a) and (b) AISI 304 steel; (c) and (d) AISI 430 steel. Reference: Paper authors. Analysis performed during this research. 
Total balance of forces: $F_{1}=F_{2}+F_{f}+F_{b}$

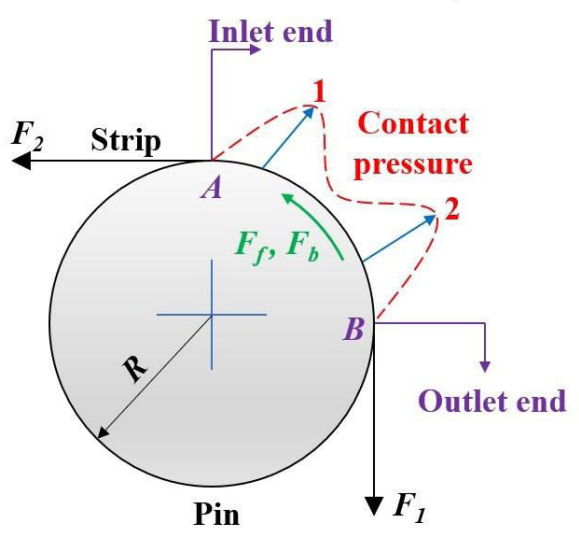

(a)

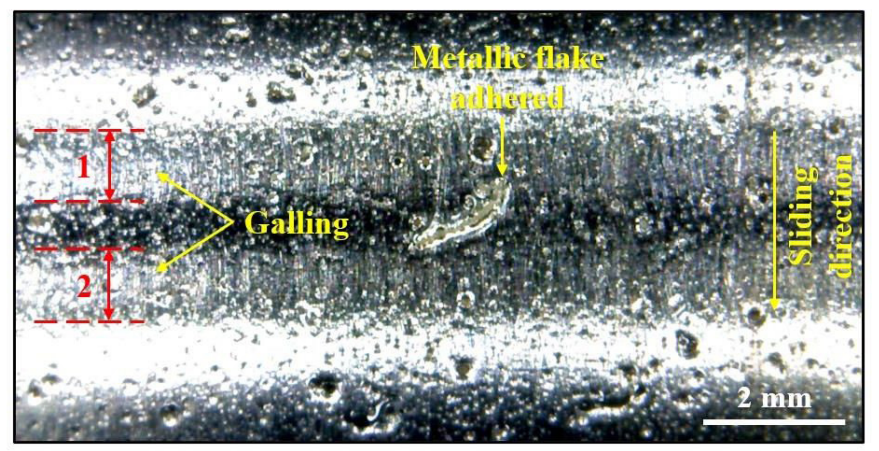

(b)

Figure 14. (a) Schematic representation of acting forces in the formability tests and contact pressure distribution (region $\mathrm{AB}$ ) on the bending pin surface and (b) Appearance final of the pin surface after severe wear. Reference: Paper authors. Analysis performed during this research.

non-uniform distribution of the contact pressure on the tool surface. In addition, Figure $13 \mathrm{~b}$ indicates that the pressure peaks appeared close to the entry (A) and exit (B) regions of the tool, that is, the beginning of bending and the end of unbending, respectively.

Kim et al.$^{54}$ determined the pressure-dependent friction coefficient from draw-bend formability tests and concluded that this behavior of the contact pressure opposes the conventional methods used determine the COF that is based on the assumptions that (i) pin/strip contact angle is equal to the geometric wrap angle, and (ii) pressure distribution at the contact is uniform. However, these assumptions are not true due to the stiffness of metal strips. Alinger et al. ${ }^{55}$ measured the strains on the outer surfaces of the strips during the draw-bend test and noticed that the real contact angle is less than the geometric wrap angle from the longitudinal strain path. Coubrough et al. ${ }^{56}$ confirmed the existence of pressure peaks using a contact sensor on the pin and they also observed that the real contact angle is less than the geometric wrap angle. Therefore, it can be concluded that the tribo-simulator was also sensitive enough to reproduce not only the minor changes in the topographic surface of the sheets, but also in the bending pin, mainly because of the variation in frictional stress and contact pressure during the relative movement between strip and pin.

\section{Conclusion}

The tribo-simulator was successfully manufactured, significant advances and advantages were obtained, and the experimental results indicated that the repeatability of the measured COFs was satisfactory (standard deviation of approximately 0.02). Therefore, that this equipment can be used to accurately measure the COF in formability tests.

In the BUT test, the measured COF for the AISI 430 steel strip was approximately $33 \%$ higher than that of the AISI 304 steel strip and $47 \%$ lower than that in the STT, most likely because of the difference in the depth and width of the ridges that formed on the surface of the FSS sheet.
In the STT test, the measured COF for the AISI 304 steel strip was approximately $44 \%$ higher than that of the AISI 430 steel strip and 29\% higher than that in the BUT test. These differences were due to the lower and higher amounts of $\alpha$-martensite transformed by the TRIP effect in the ASS sheet surface, respectively.

The texture directionality also influenced the measured $\mathrm{COF}$, and the most pronounced differences were due to the mechanical properties and surface roughness of the stainlesssteel sheets. The ASS sheet exhibited a greater COF in the $90^{\circ}$ direction in both tests, while that of the FSS sheet was greater in the $0^{\circ}$ direction in the BUT test.

The micro-effects of the friction and wear mechanisms were more intense for the strips subjected to the BUT test because the higher contact pressure broke the lubricating film more easily, increasing the galling level owing to severe adhesive wear. Moreover, the pressure distribution at the tribocontact was non-uniform.

Considering that the stainless-steel sheets exhibited different tribological behaviors, the measured COFs could be used to improve the accuracy of numerical simulations and, consequently, the productivity and quality of manufactured products.

\section{Acknowledgements}

The authors would like to thank CEFET (Federal Center for Technological Education) and UFMG (Federal University and Minas Gerais) for their technical support and allowing the use of their equipment. The authors also thank Aperam South America, Timóteo, Minas Gerais, Brazil, for providing the Samples used in this study.

\section{References}

1. Gronostajski Z, Pater Z, Madej L, Gontarz A, Lisiecki L, Lukaszek-Solek A, et al. Recent development trends in metal forming. Arch Civ Mech Eng. 2019;19(3):898-941.

2. Trzepieciński T. Recent developments and trends in sheet metal forming. Metals. 2020;10(6):779. 
3. Sigvant M, Pilthammar J, Hol J, Wiebenga JH, Chezan T, Carleer B, et al. Friction in sheet metal forming: influence of surface roughness and strain rate on sheet metal forming simulaion results. Procedia Manuf. 2019;29:512-9.

4. Evin E, Németh S, Výrostek M. Evaluation of friction coefficient of stamping. Acta Mech Slovaca. 2014;18(3-4):20-7.

5. Evin E, Tomáš M, Výrostek M. Verification the numerical simulation of the strip drawing test by its physical model. Acta Mech Slovaca. 2016;20(1):14-21.

6. Evin E, Daneshjo N, Mareš A, Tomáš M, Petrovčiková K. Experimental assessment of friction coefficient in deep drawing and its verification by numerical simulation. Appl Sci. 2021;11(6):2756.

7. Kirkhorn L, Bushlya V, Andersson M, Stahl J-E. The influence of tool steel microstructure on friction in sheet metal forming. Wear. 2013;302(1-2):1268-78.

8. Kim H, Kardes N. Friction and lubrication. In: Altan T, Tekkaya AE, editors. Sheet metal forming: fundamentals. Ohio: ASM International; 2012. p. 89-103.

9. Trzepiecinski T, Lemu HG. Recent developments and trends in the friction testing for conventional sheet metal forming and incremental sheet forming. Metals. 2020;10(1):1-34.

10. Lo KH, Shek CH, Lai JKL. Recent developments in stainless steels. Mater Sci Eng Rep. 2009;65(4-6):39-104.

11. International Stainless Steel Forum - ISSF. The ferritic solution: properties, advantages, applications [Internet]. 2007 [cited 2021 Jan 10]. Available from: https://www.worldstainless.org/Files/ issf/non-imagefiles/PDF/ISSF_The_Ferritic_Solution_English. pdf

12. Tanure LPAR, Alcântara CM, Oliveira TR, Santos DB, Gonzalez BM. Microstructure, texture and microhardness evolution during annealing heat treatment and mechanical behavior of the niobium-stabilized ferritic stainless steel ASTM 430 and niobium-titanium-stabilized ferritic stainless steel ASTM 439: a comparative study. Mater Res. 2017;20(6):1650-7.

13. Vallance DW, Matlock DK. Application of the bending-undertension friction test to coated sheet steels. J Mater Eng Perform. 1992;1(5):685-93.

14. Fratini L, Lo Casto S, Lo Valvo E. A technical note on an experimental device to measure friction coefficient in sheet metal forming. J Mater Process Technol. 2006;172(1):16-21.

15. Interlaken. Bend tester [Internet]. 2007 [cited 2021 Aug 30]. Available from: https://interlaken.com/docs/Bend\%20Tester. pdf

16. Racz SG, Khan S, Chalal H, Abed-Meraim F, Balan T. Prediction of springback after draw-bending test using different material models. In: International Conference on Advances in Materials and Processing Technologies; 2010; Paris, France. Proceedings. College Park: American Institute of Physics; 2010. p. 419-24.

17. Barthel C, Clausmeyer T, Svendsen B. Numerical investigation of draw bending and deep drawing taking into account cross hardening. In: 7th European LS-DYNA Conference; 2009; Salzburg, Austria. Proceedings. Stuttgart: DYNAmore GmbH; 2009.

18. Folle LF, Schaeffer L. New proposal to calculate the friction in sheet metal forming through bending under tension test. Mater Res. 2019;22(6):e20190523.

19. Dou L, Li X, Dong H, Li D, Peng X. Development of springback tester and the effect of forming speed on the springback of four sheet metal bending processes. Mater Sci Eng. 2020;967:012065.

20. Sanchez-Caballero S, Selles M, Pla-Ferrando R, Seguí J, Peydro M. Research on the friction properties of dp600 stainless steel as a function of bending angle and pin diameter. Materials Proceedings. 2021;3(1):17.

21. Trzepiecinski T. A study of the coefficient of friction in steel sheets forming. Metals. 2019;9(9):988.

22. Sniekers RJJM. Friction in deep drawing [dissertation]. Eindhoven: Technische Universiteit Eindhoven; 1996.
23. Wagoner RH, Lim H, Lee MG. Advanced Issues in springback. Int J Plast. 2013;45:3-20.

24. Moghadam M, Suleiman MH, Christiansen P, Bay N. Acoustic emission monitoring of the bending under tension test. Procedia Eng. 2017;207:1421-6.

25. Sung JH, Kim JH, Wagoner RH. The draw-bend fracture test and its application to dual-phase and transformation induced plasticity steels. J Eng Mater Technol. 2012;134:1-15.

26. Hakoyama CS, Hakoyama T, Fukiharu H, Kuwabara T. Fracture prediction for mild steel sheet and high-strength steel sheet subjected to draw bending using forming limit stress criterion. J Mater Process Technol. 2021;287:116313.

27. Vega MRO, Parise K, Ramos LB, Boff U, Mattedi S, Schaeffer $\mathrm{L}$, et al. Protic ionic liquids used as metal-forming green lubricants for aluminum: effect of anion chain length. Mater Res. 2017;20(3):675.

28. Trzepiecinski T, Lemu HG. Effect of lubrication on friction in bending under tension test-experimental and numerical approach. Metals. 2020;10(4):544.

29. Sulaiman MH, Farahana RN, Bienk K, Nielsen CV, Bay N. Effects of DLC/TiAlN-coated die on friction and wear in sheet-metal forming under dry and oil-lubricated conditions: experimental and numerical studies. Wear. 2019;438-439:203040.

30. American Society for Testing and Materials-ASTM. ASTM E8/ E8M-16a: standard test methods for tension testing of metallic materials. West Conshohocken: ASTM International; 2016.

31. Banabic D, Bunge H-J, Pöhlandt K, Tekkaya AE. Formability of metallic materials. engineering materials. Berlin: Springer; 2000.

32. Andreasen JL, Olsson DD, Chodnikiewicz K, Bay N. Bending under tension test with direct friction measurement. Proc Inst Mech Eng, B J Eng Manuf. 2006;220(1):73-80.

33. Kim JH, Sung JH, Matlock DK, Kim D, Wagoner RH. Finite element and analytical study of plane strain draw-bend failure of advanced high strength steels. Int J Mater Form. 2010;3(1):18790.

34. Masters LG, Williams DK, Roy R. Friction behaviour in strip draw test of pre-stretched high strength automotive aluminium alloys. Int J Mach Tools Manuf. 2013;73:17-24.

35. Garrison WN Jr, Moody NR. Ductile fracture. J Phys Chem Solids. 1987;48(11):1035-74.

36. Bhushan B. Introduction to tribology. 2nd ed. New York: John Wiley \& Sons; 2013.

37. Ferrarini JL. Análise e determinação do coeficiente de atrito no processo de estampagem profunda [dissertation]. Porto Alegre: Universidade Federal do Rio Grande do Sul; 2014.

38. Shin HJ, An JK, Park SH, Lee DN. The effect of texture on ridging of ferritic stainless steel. Acta Mater. 2003;51(16):4693706.

39. Oliveira TR, Cunha MA, Gonçalves IN. Estriamento (roping) em aços inoxidáveis ferríticos AISI 430 estabilizados ao nióbio. Tecnol Metal Mater Min. 2009;5(3):150-5.

40. Kodukula S, Ohligschläger T, Porter D. Quantification of the severity of ridging in ferritic stainless steel sheets using a profilometric technique. ISIJ Int. 2021;61(1):380-6.

41. Bleck W, Guo X, Ma Y. The TRIP effect and its application in cold formable sheet steels. Steel Res Int. 2017;88(10):1700218.

42. Padilha AF, Rios PR. Decomposition of austenite in stainless steel. ISIJ Int. 2002;42(4):325-7.

43. Abreu HFG, Carvalho SS, Lima P No, Santos RP, Freire VN, Silva PMO, et al. Deformation induced martensite in an AISI $301 \mathrm{LN}$ stainless steel: characterization and influence on pitting corrosion resistance. Mater Res. 2007;10(4):359-66.

44. Lischka FT, Oliveira CAS. The study of TRIP effect in an austenitic stainless steel AISI 304. J Achiev Mater Manuf Eng. 2015;71(1):34-8.

45. Zabala A, Galdos L, Childs C, Llavori I, Aginagalde A, Mendiguren $\mathrm{J}$, et al. The interaction between the sheet/tool 
surface texture and the friction/galling behaviour on aluminium deep drawing operations. Metals. 2021;11(6):979.

46. Gåård A, Krakhmalev PV, Bergström J, Hallbäck N. Galling resistance and wear mechanisms: cold work tool materials sliding against carbon steel sheets. Tribol Lett. 2007;26(1):67-72.

47. Velkavrh I, Lüchinger M, Kern K, Klien S, Ausserer F, Voyer $\mathrm{J}$, et al. Using a standard pin-on-disc tribometer to analyse friction in a metal forming process. Tribol Int. 2017;114:418-28.

48. Ter Haar R. Friction in sheet metal forming: the influence of (local) contact conditions and deformation [dissertation]. Enschede: University of Twente; 1996.

49. Cora Ö, Ağcayazı A, Namiki K, Sofuoğlu H, Koç M. Die wear in stamping of advanced high strength steels-Investigations on the effects of substrate material and hard-coatings. Tribol Int. 2012;52:50-60.

50. Blau PJ. Friction science and technology: from concepts to applications. 2nd ed. Florida: CRC Press; 2008.
51. Rabinowicz E. Friction and wear of materials. 2nd ed. New York: John Wiley \& Sons; 1995.

52. Suh NP. The delamination theory of wear. Wear. 1973;25(1):111-24.

53. Suh NP. An overview of the delamination theory of wear. Wear. 1977;44(1):1-16.

54. Kim YS, Jain MK, Metzger DR. Determination of pressure-dependent friction coefficient from draw-bend test and its application to cup drawing. Int J Mach Tools Manuf. 2012;56:69-78.

55. Alinger MJ, Sriram S, Matlock DK. An investigation of strain evolution in the bending-under-tension friction test. In: Sheet Metal Forming Technology; 1999; San Diego, California. Proceedings. Warrendale: Minerals, Metals and Materials Society/AIME; 1999. p. 129-40.

56. Coubrough GJ, Alinger MJ, Van Tyne CJ. Angle of contact between sheet and die during stretch-bend deformation as determined on the bending-under-tension friction test system. J Mater Process Technol. 2002;130-131:69-75. 